\title{
Effects of total body irradiation-based conditioning on allogeneic stem cell transplantation for pediatric acute leukemia: a single-institution study
}

\author{
Jongmoo Park, MD, PhD, Eun Kyung Choi, MD, Jong Hoon Kim, MD, Sang-wook Lee, MD, PhD, \\ Si Yeol Song, MD, PhD, Sang Min Yoon, MD, Young Seok Kim, MD, PhD, Su Ssan Kim, MD, PhD, \\ Jin-hong Park, MD, PhD, Jaehyeon Park, MD, Seung Do Ahn, MD, PhD \\ Department of Radiation Oncology, Asan Medical Center, University of Ulsan College of Medicine, Seoul, Korea
}

Purpose: To evaluate the effects of total body irradiation (TBI), as a conditioning regimen prior to allogeneic stem cell transplantation (allo-SCT), in pediatric acute leukemia patients.

Materials and Methods: From January 2001 to December 2011, 28 patients, aged less than 18 years, were treated with TBIbased conditioning for allo-SCT in our institution. Of the 28 patients, 21 patients were diagnosed with acute lymphoblastic leukemia (ALL, 75\%) and 7 were diagnosed with acute myeloid leukemia (AML, 25\%). TBI was completed 4 days or 1 day before stem cell infusion. Patients underwent radiation therapy with bilateral parallel opposing fields and 6-MV X-rays. The Kaplan-Meier method was used to calculate survival outcomes.

Results: The 2-year event-free survival and overall survival rates were $66 \%$ and $56 \%$, respectively $(71.4 \%$ and $60.0 \%$ in AML patients vs. $64.3 \%$ and $52.4 \%$ in ALL patients, respectively). Treatment related mortality rate were $25 \%$. Acute and chronic graftversus-host disease was a major complication; other complications included endocrine dysfunction and pulmonary complications. Common complications from TBI were nausea (89\%) and cataracts (7.1\%).

Conclusion: The efficacy and toxicity data in this study of TBI-based conditioning to pediatric acute leukemia patients were comparable with previous studies. However, clinicians need to focus on the acute and chronic complications related to allo-SCT.

Keywords: Total body irradiation, Acute lymphoid leukemia, Acute myeloid leukemia, Child, Stem cell transplantation

\section{Introduction}

Acute leukemia is the most common pediatric cancer, of which acute lymphoblastic leukemia (ALL) is more common than acute myeloid leukemia (AML). The cure rate of acute leukemia has steadily improved since the use of intensive chemotherapy and the 5 -year survival rate is now estimated to be more than $85 \%$ for ALL [1] and 57\% for AML patients $[2,3]$. Allogeneic stem-cell transplantation (allo-SCT) is now the treatment of choice for patients with high-risk disease and low survival expectancy with chemotherapy alone $[4,5]$. Prior to transplantation, conditioning therapy must sufficiently suppress the recipient's immunity to allow sustained engraftment, prevent rejection, and eradicate neoplastic cells.

Received 7 May 2014, Revised 30 June 2014, Accepted 1 September 2014.

Correspondence: Seung Do Ahn, MD, PhD, Department of Radiation Oncology, Asan Medical Center, University of Ulsan College of Medicine, 88 Olympic-ro 43-gil, Songpa-gu, Seoul 138-736, Korea. Tel: +82-2-3010-4427, Fax: +82-2-3010-6950, Email:sdahn@amc.seoul.kr

(c) This is an Open Access article distributed under the terms of the Creative Commons Attribution Non-Commercial License (http://creativecommons.org/ licenses/by-nc/3.0/) which permits unrestricted non-commercial use, distribution, and reproduction in any medium, provided the original work is properly cited.

www.e-roj.org 
Table 1. Patient, disease, and transplantation characteristics (n $=28$ )

\begin{tabular}{|c|c|}
\hline Characteristic & Value \\
\hline Age (yr) & $8(3-15)$ \\
\hline \multicolumn{2}{|l|}{ Sex } \\
\hline Male & $15(53.6)$ \\
\hline Female & $13(46.4)$ \\
\hline \multicolumn{2}{|l|}{$\operatorname{ALL}(n=21)$} \\
\hline CR1 & $13(61.9)$ \\
\hline T-ALL & 4 \\
\hline $\mathrm{t}(9 ; 22)$ & 8 \\
\hline Slow remission & 4 \\
\hline Age $\geq 10$ y & 7 \\
\hline$\geq \mathrm{CR} 2$ & $8(38.1)$ \\
\hline \multicolumn{2}{|l|}{$\operatorname{AML}(n=7)$} \\
\hline CR1 & $4(57.1)$ \\
\hline$\geq \mathrm{CR} 2$ & $3(42.9)$ \\
\hline \multicolumn{2}{|l|}{ ECOG performance statue } \\
\hline 0 & $3(10.7)$ \\
\hline 1 & 21(81.1) \\
\hline 2 & $2(7.2)$ \\
\hline$\leq 3$ & $0(0)$ \\
\hline BM & $7(25.0)$ \\
\hline MSD / MUD & $1 / 6$ \\
\hline PB & $18(64.3)$ \\
\hline MSD / MUD & $3 / 15$ \\
\hline UCB & $3(10.7)$ \\
\hline \multicolumn{2}{|l|}{ Myeloablative conditioning } \\
\hline 13.2 Gy (1.65 Gy × 8 fraction, twice daily) & $19(67.8)$ \\
\hline 12.0 Gy (1.5 Gy × 8 fraction, twice daily) & $6(21.4)$ \\
\hline 13.5 Gy (1.5 Gy × 9 fraction, twice daily) & $1(3.6)$ \\
\hline 8.0 Gy (2.0 Gy × 4 fraction, once daily) & $1(3.6)$ \\
\hline \multicolumn{2}{|l|}{ Non-myeloablative conditioning } \\
\hline 3.0 Gy (1.5 Gy × 2 fraction, twice daily) & $1(3.6)$ \\
\hline
\end{tabular}

Values are presented as median (range) or number (\%).

$A L L$, acute lymphoblastic leukemia; $A M L$, acute myeloid leukemia; $A B L$, acute biphenotypic leukemia; $C R$, complete remission; ECOG, Eastern Cooperative Oncology Group; BM, bone marrow; UCB, umbilical cord blood; PB, peripheral blood stem cell; MSD, matched sibling donor; MUD, matched unrelated donor.

Although consensus is yet to be reached, conditioning for allo-SCT is currently classified as follows: myeloablative conditioning, reduced intensity conditioning (RIC), and nonmyeloablative conditioning. However, there is no standard choice of conditioning for allo-SCT and the decision is based upon recipient comorbidities, underlying conditions and disease status, donor, and graft. RIC is known to significantly reduce of treatment related mortality (TRM) although relapse rates after RIC may be higher [6-8]. In comparison with adult patients, RIC and non-myeloablative conditioning are yet to be established in pediatric patients. Myeloablative conditioning continues to be the preferred regimen in pediatric patients. These conditioning regimens consist of chemotherapy and total body irradiation (TBI), which varies in total dose, dose rate, fraction size, and number of fraction for each conditioning regimen.

Two-thirds of long-term survivors reportedly develop TBIrelated complications, including growth retardation, hormonal imbalance, neurological disorders, infertility, and secondary cancer. However, the efficacy and long-term influence of TBI based conditioning in Korean pediatric leukemia patients is not well remains poorly reported. Also, the effects on different types of leukemia are not well known. The aim of this study was to evaluate the effects of TBI-based conditioning prior to allo-SCT to pediatric acute leukemia patients.

\section{Materials and Methods}

We retrospectively reviewed 28 patients younger than 18 years with acute leukemia (21 ALL and $7 \mathrm{AML}$ patients), who had received TBI-based conditioning for allo-SCT at our institution between January 2001 and December 2011. Patient characteristics are summarized in Table 1. All patients were in complete remission at the time of allo-SCT including a first complete remission (CR1) and a second or higher remission $(\geq \mathrm{CR} 2)$ after a first or higher relapse.

Conditioning chemotherapy was started 21 days before stem cell infusion (D-21). Patients were hospitalized for allo-SCT on D-8. TBI was completed at D-4 for myeloablative conditioning and on D-1 for non-myeloablative conditioning (Fig. 1). Chemotherapy regimens comprised either a single agent or a combination of agents.

Patients were placed in the supine position with whole-body vacuum immobilization, and some patients required kneelocking (Fig. 2A). Whole body images were obtained using a computed tomography (CT) simulator. An individualized lead compensator (Fig. 2B) was used to homogenize the wholebody dose to within $\pm 5 \%$ in all patients. Treatment was administered using a linear accelerator with 6-MV X-rays, bilateral parallel opposing fields and extended SAD $(475 \mathrm{~cm})$. Thermoluminescence dosimetry was applied to the head, neck, chest (surface and lateral), umbilicus (left and right), pelvis, and to the medial sides of the thigh, knee, and malleolus.

Of all 28 patients, 27 (96.4\%) underwent myeloablative conditioning and 1 (3.6\%) underwent non-myeloablative 

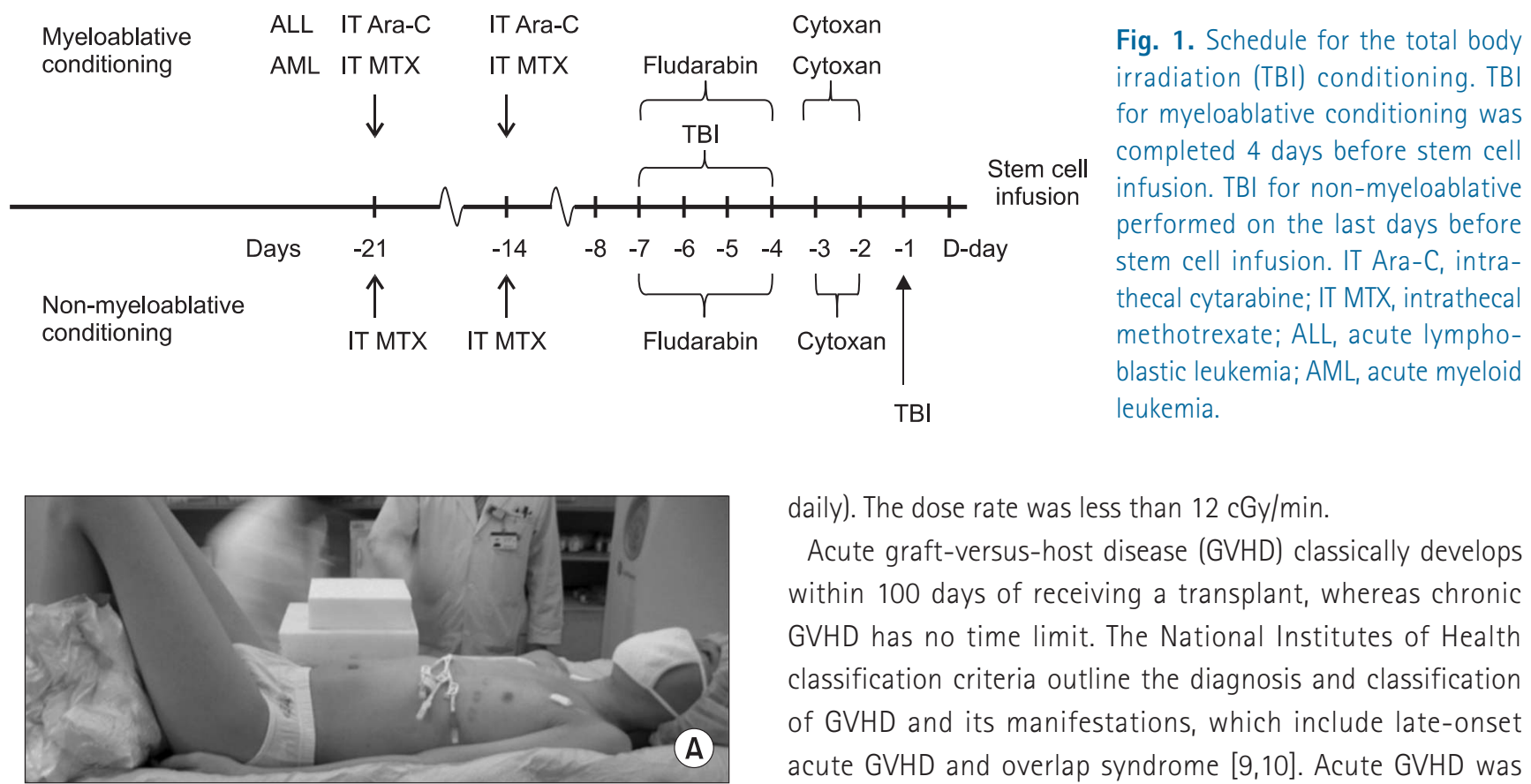

daily). The dose rate was less than $12 \mathrm{cGy} / \mathrm{min}$.

Acute graft-versus-host disease (GVHD) classically develops within 100 days of receiving a transplant, whereas chronic GVHD has no time limit. The National Institutes of Health classification criteria outline the diagnosis and classification of GVHD and its manifestations, which include late-onset acute GVHD and overlap syndrome $[9,10]$. Acute GVHD was diagnosed and graded according to Thomas et al's criteria [10-
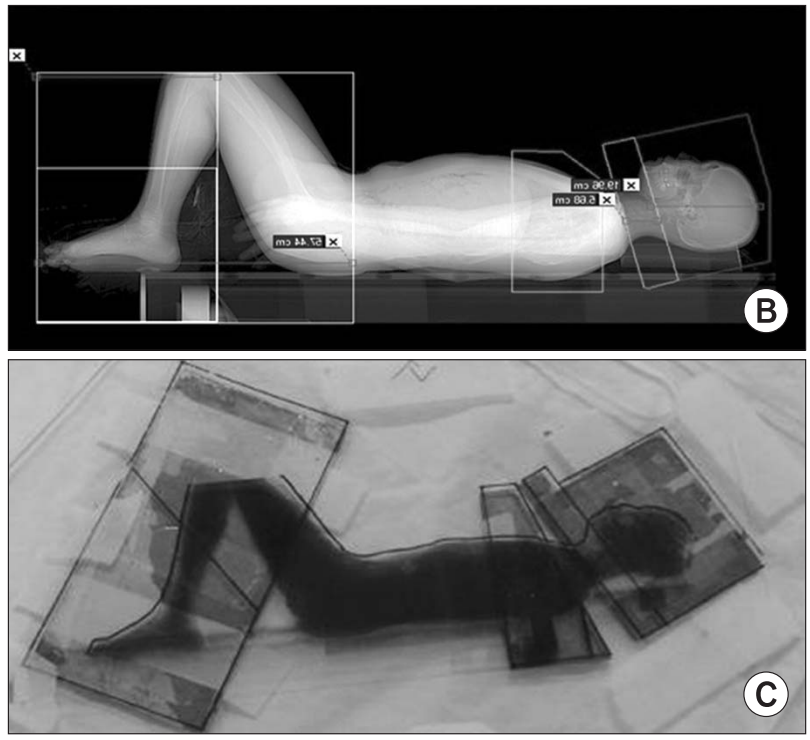

Fig. 2. Total body irradiation (TBI) technique. (A) The patient in a supine position with his/her both knees bent. (B) Scout image obtained from CT simulation. (C) Individualized compensator mounted accessory tray. 12]. Severity was graded from $0-I V$, depending on invasion to the liver, skin, mucosa, and gastrointestinal tract (Table 2). Chronic GVHD was classified as limited or extensive according to Shulman et al.'s criteria [13] (Table 3).

TRM was defined as death due to causes other than relapse or refractory disease, such as infection, hemorrhage, organ failure, and metabolic abnormality (mainly tumor lysis syndrome). TRM included not only death unrelated to refractory or progressive disease before achieving remission, but also any death in CR.

Overall survival (OS) was defined as the relapsed time from the day of stem cell infusion to death. Event-free survival (EFS) was defined as the relapsed time from the day of stem cell infusion to disease relapse or graft failure. Survival analysis was performed by the Kaplan-Meier method and SPSS ver. 21 (IBM, Armonk, NY, USA).

\section{Results}

\section{Patient and treatment results}

conditioning. The doses of TBI for myeloablative conditioning were 13.2 Gy (1.65 Gy/fraction, twice daily, 19 patients), 12 Gy (1.5 Gy/fraction, twice daily, 6 patients), 8 Gy (2 Gy/fraction, once daily, 1 patient), and 13.5 Gy (1.5 Gy/fraction, twice daily and once on the last day, 1 patient). The dose of TBI for nonmyeloablative conditioning was $3 \mathrm{~Gy}$ (1.5 Gy/fraction, twice

An overview of patient, disease and transplantation characteristics are shown in Table 1. The median follow-up period was 16.1 months (range, 1 to 71 months). Twenty-one ALL patients (61.9\%) and 4 AML patient (57.1\%) had previously undergone remission. Thirteen patients who received alloSCT in CR1 fulfilled high risk or very high risk features, such 
Table 2. Grading of acute GVHD

\begin{tabular}{clll}
\hline Stage & \multicolumn{1}{c}{ Skin } & Liver (bilirubin) & \multicolumn{1}{c}{ Gl (stool output/day) } \\
\hline 0 & No GVHD rash & $<2 \mathrm{mg} / \mathrm{dL}$ & $<500 \mathrm{~mL} /$ day or persistent nausea \\
1 & Maculopapular rash $<25 \% \mathrm{BSA}$ & $2-3 \mathrm{mg} / \mathrm{dL}$ & $500-999 \mathrm{~mL} /$ day \\
2 & Maculopapular rash 25\%-50\% BSA & $3.1-6 \mathrm{mg} / \mathrm{dL}$ & $1,000-1,500 \mathrm{~mL} / \mathrm{day}$ \\
3 & Maculopapular rash $>50 \% \mathrm{BSA}$ & $6.1-15 \mathrm{mg} / \mathrm{dL}$ & Adult: $>1,500 \mathrm{~mL} /$ day \\
4 & Generalized erythroderma plus bullous formation & $>15 \mathrm{mg} / \mathrm{dL}$ & Severe abdominal pain with or without ileus \\
\hline Grade & & & \\
I & Stage 1-2 & None & None \\
II & Stage 3 or & Stage 1 or & Stage 1 or \\
III & - & Stage 2-3 or & Stage 2-4 \\
IV & Stage 4 or & Stage 4 & ECOG0 \\
\hline
\end{tabular}

GVHD, graft-versus-host disease; BSA, body surface area; Gl, gastrointestinal; ECOG, Eastern Cooperative Oncology Group.

Table 3. Grading of chronic GVHD

\begin{tabular}{ll}
\hline Grade & \\
\hline Limited disease & Localized skin involvement and/or evidence of hepatic dysfunction. \\
Extensive disease & Generalized skin involvement, or with localized skin involvement or hepatic dysfunction plus at least one \\
& of the following: \\
& - Liver histology showing chronic progressive hepatitis, bridging necrosis, or cirrhosis \\
& - Involvement of the eye \\
& - Involvement of minor salivary glands or oral mucosa \\
& - Involvement of any other target organ
\end{tabular}

GVHD, graft-versus-host disease.

A

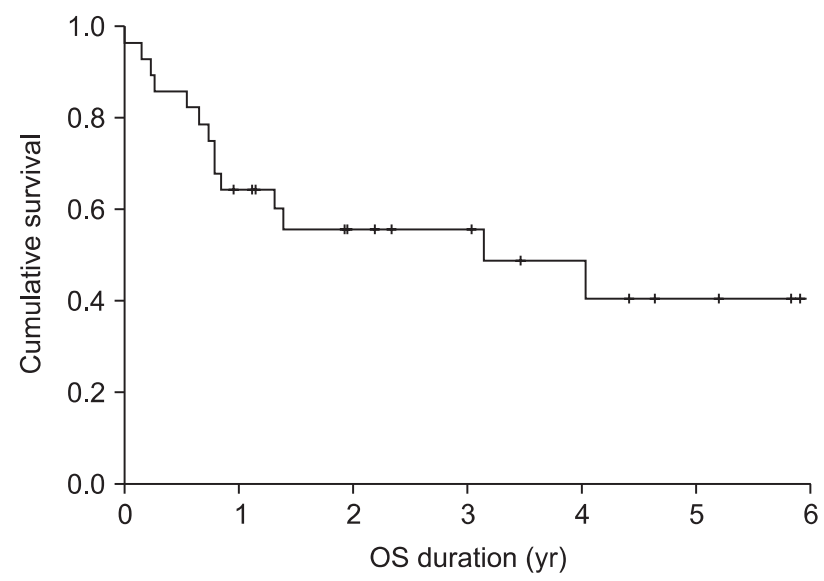

B

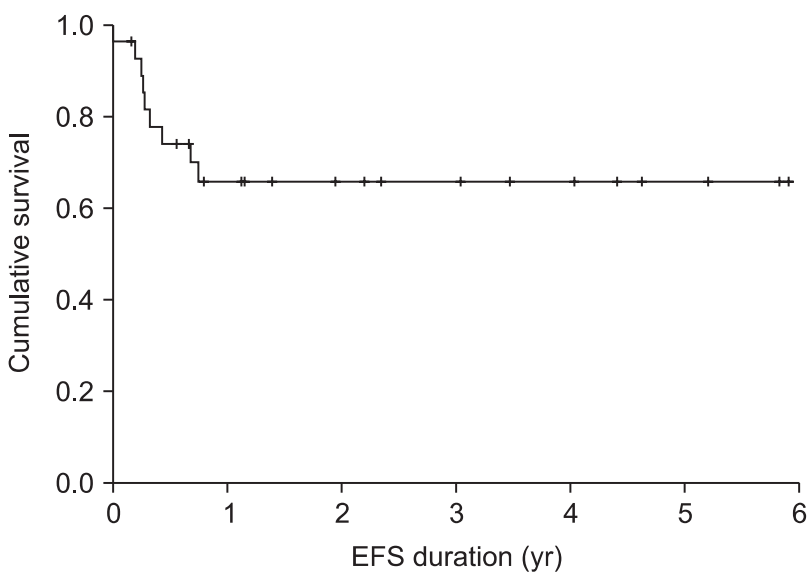

Fig. 3. (A) The 2-year event-free survival (EFS) of 66\%. (B) The 2-year overall survival (OS) rate of 56\%.

as T-ALL, t(9;22), slow remission and more than 10 years older. Fifteen patients were more than CR2. The Eastern Cooperative Oncology Group performance status prior to allo-SCT was 0 in 3 patients (10.7\%), 1 in 21 patients (81.1\%) and 2 in 2 patients (7.2\%). The stem cell source was the bone marrow (BM) in 7 patients (25.0\%), peripheral blood stem cells (PB) in 18 patients (64.3\%), and umbilical cord blood (UCB) in 3 patients (10.7\%). Engraftment was achieved in $92.9 \%$ of patients with neutrophil (absolute neutrophil count $\geq 1,000 / \mu \mathrm{L}$ ) and platelet $(\geq 20,000 / \mu \mathrm{L})$ recovery occurring at a median of 14 and 23 days, respectively.

The 2-year EFS and OS rates were 66\% and 56\%, respectively 
A

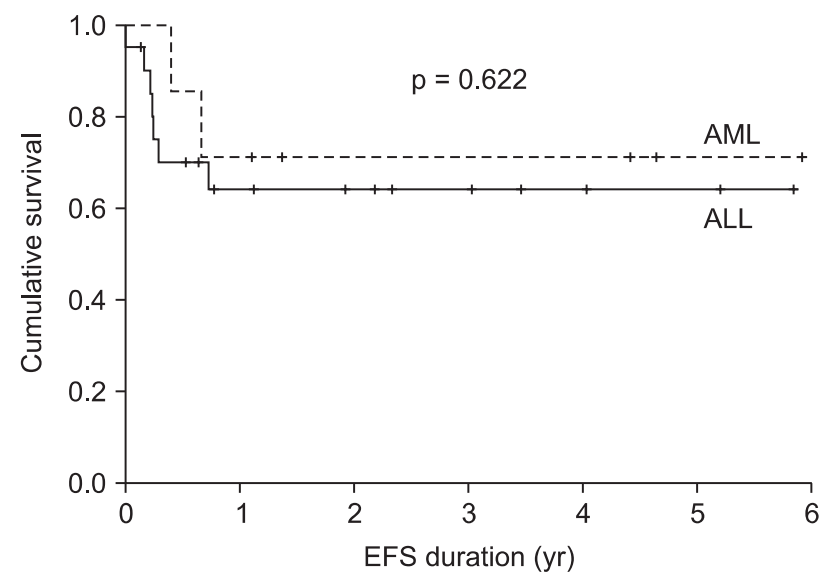

C

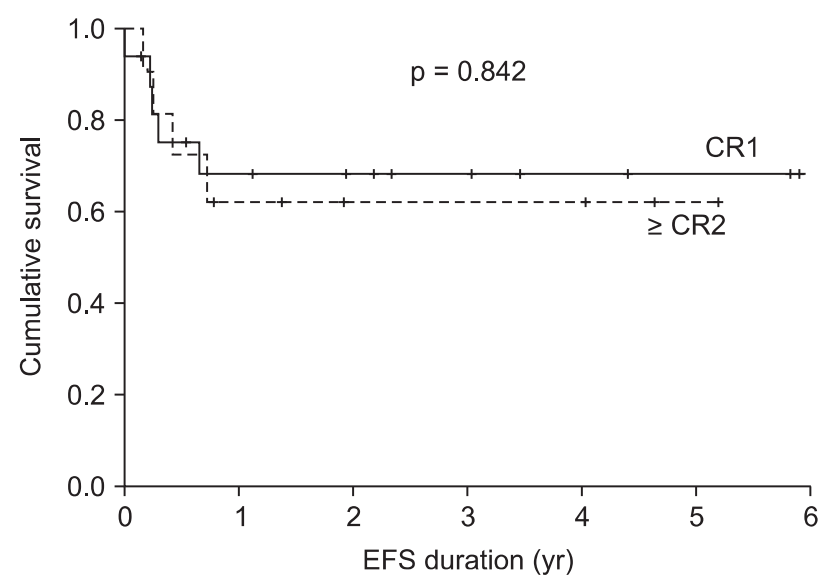

E

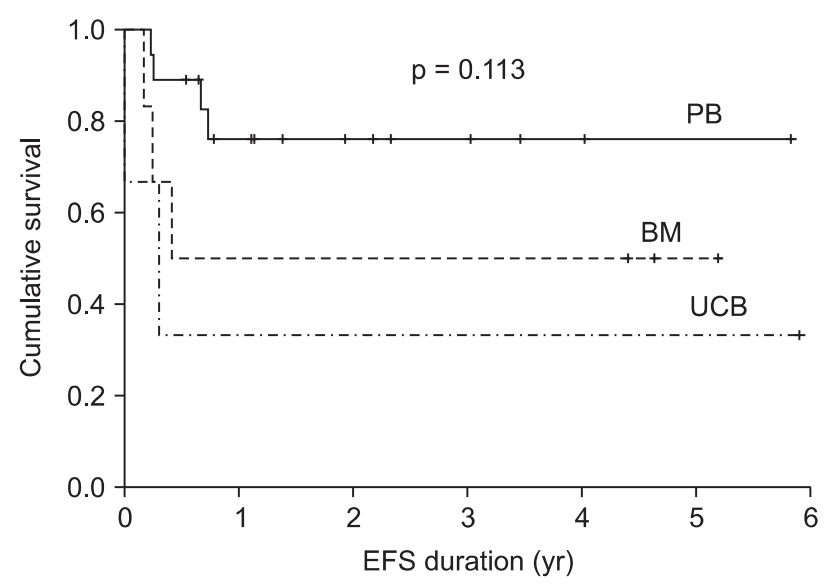

B

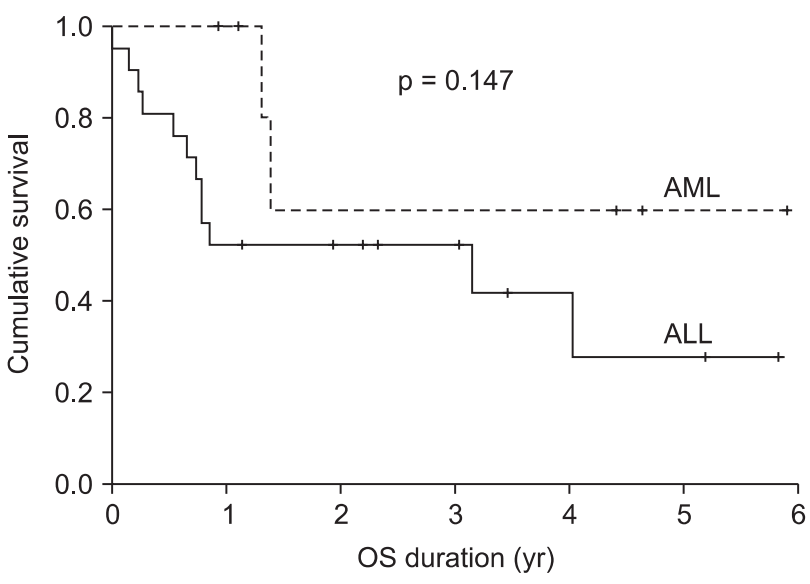

D

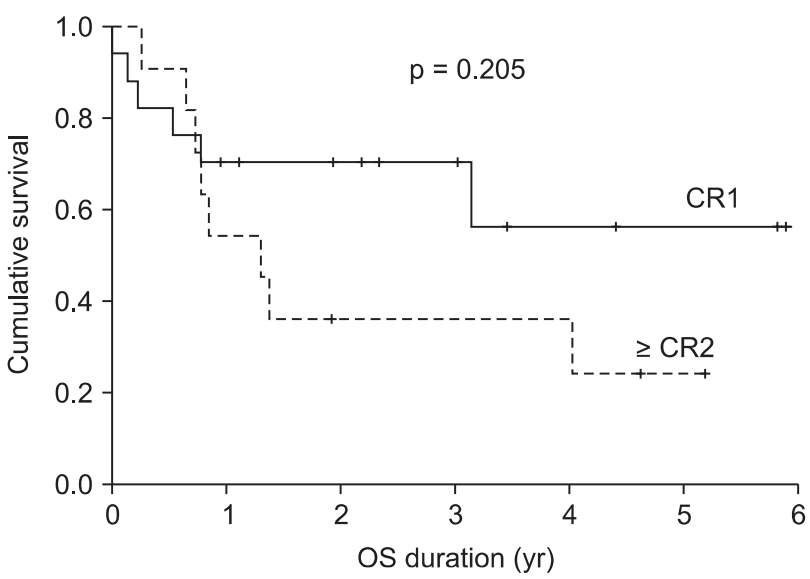

F

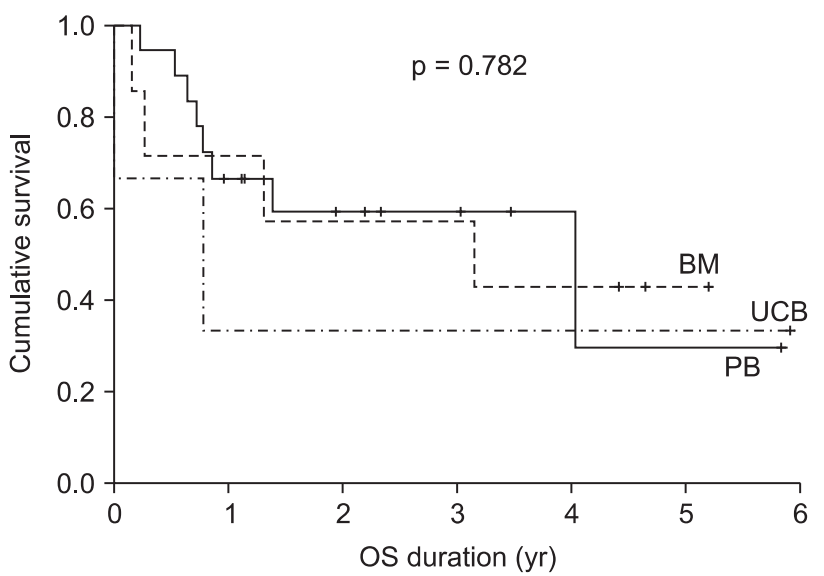

Fig. 4. Two-year event-free survival (EFS) and 2-year overall survival (OS) outcomes in accordance with leukemia type, remission status, and source of transplantation. (A) The 2-year EFS values were 71.4\% and 60.0\% for AML and ALL, respectively. (B) The 2-year OS values for AML and ALL were $64.3 \%$ and $52.4 \%$. (C) The 2-year EFS values for CR and $\geq C R 2$ were $68.4 \%$ and $62.3 \%$. (D) The 2-year OS values for $C R$ and $\geq C R 2$ were $70.6 \%$ and 36.4\%. (E) The 2-year EFS values for stem cell transplantations from the PB, BM, and UCB were 59.3\%, 57.1, and 33.3\%. (F) The 2-year OS values for stem cell transplantations from the PB, BM, and UCB were 76.2\%, 50.0, and 33.3\%. ALL, acute lymphoblastic leukemia; $A M L$, acute myeloid leukemia; $C R$, complete remission; $B M$, bone marrow; $U C B$, umbilical cord blood; $P B$, peripheral blood. 
Table 4. Causes of death

\begin{tabular}{lccc}
\hline & Total $(n=28)$ & ALL $(n=21)$ & AML $(n=7)$ \\
\hline Relapse-related & $6(21.4)$ & $4(19.0)$ & $2(28.6)$ \\
Treatment-related & $7(25.0)$ & $7(33.3)$ & $0(0)$ \\
Pneumonia & $2(7.1)$ & $2(9.5)$ & $0(0)$ \\
Engraft failure & $1(3.6)$ & $1(4.7)$ & $0(0)$ \\
Disseminated fungal infection & $1(3.6)$ & $1(4.7)$ & $0(0)$ \\
Hemolytic uremic syndrome & $1(3.6)$ & $1(4.7)$ & $0(0)$ \\
Acute respiratory distress syndrome & $1(3.6)$ & $1(4.7)$ & $0(0)$ \\
Hepatorenal syndrome (AML) & $1(3.6)$ & $1(4.7)$ & $0(0)$ \\
\hline
\end{tabular}

Values are presented as number (\%).

ALL, acute lymphoblastic leukemia; AML, acute myeloid leukemia; treatment-related, defined as any death not because of progressive disease.

(Fig. 3) and were compared according to leukemia type, remission status, and source for transplantation (Fig. 4). For the type of leukemia, the 2-year EFS and OS rates were $71.4 \%$ and $64.3 \%$ for $A M L$, and $60.0 \%$ and $52.4 \%$ for ALL, respectively. In terms of remission status, the 2-year EFS and OS rates were $68.4 \%$ and $70.6 \%$ for CR1, and $62.3 \%$ and $36.4 \%$ for $\geq C R 2$, respectively. While considering the source for transplantation, these values were $59.3 \%$ and $76.2 \%$ for $P B, 57.1 \%$ and $50.0 \%$ for $\mathrm{BM}, 33.3 \%$ and $33.3 \%$ for $\mathrm{UCB}$, respectively.

In total, 13 patients died after allo-SCT, 6 of leukemic relapse and 7 due to TRM, notably, all 13 were ALL patients. The total TRM rate was 25\% (7/28 patients). Causes of transplantrelated deaths included pneumonia, graft failure, infection, hemolytic uremic syndrome, acute respiratory distress syndrome, and hepatorenal syndrome (Table 4).

\section{Complications}

The complications are summarized in Table 5. Acute complications from TBI were nausea in 25 patients (89.2\%), and vomiting in 10 patients (35.7\%). Chronic complications from TBI developed in 5 patients (17.9\%) (Table 6).

Two patients had multiple complications-short stature (defined as the third percentile of standard height), cataracts, and hepatic veno-occlusive disease (VOD) in one patient, and cataracts and short stature in the other patient.

Short stature was most common chronic complication from TBI (defined as the third percentile of standard height) in 4 patients. Two patients (7.1\%) suffered hepatic VOD. Two patients (7.1\%) developed cataracts after 25 and 32 months after TBI. Secondary neoplasm did not develop. Acute GVHD with a grade higher than 2 developed in 11 patients (39.3\%). Chronic GVHD (extensive or limited) developed in 15 patients (53.6\%). Acute complications other than GVHD developed in
Table 5. Allogeneic stem cell transplantation related complications $(n=28)$

\begin{tabular}{lc}
\hline \multicolumn{1}{c}{ Characteristic } & No. of patients (\%) \\
\hline Acute GVHD & $17(60.7)$ \\
Grade I & $6(21.4)$ \\
Grade II-IV & $11(39.3)$ \\
Chronic GVHD & $15(53.6)$ \\
Limited & $3(10.7)$ \\
Extensive & $12(42.9)$ \\
Non-GVHD acute complication & \\
Nausea & $25(89.2)$ \\
CMV infection & $13(46.4)$ \\
GI mucositis & $8(28.6)$ \\
Nephropathy & $6(21.4)$ \\
Hepatic VOD & $2(7.1)$ \\
Seizure & $2(7.1)$ \\
Hemorrhagic cystitis & $1(3.6)$ \\
Other & $4(14.3)$ \\
Non-GVHD chronic complications & \\
Endocrine dysfunction & $5(17.9)$ \\
Interstitial pneumonitis & $5(17.9)$ \\
Short stature & $4(14.3)$ \\
Cataract & $2(7.1)$ \\
\hline
\end{tabular}

Acute GVHD <100 days after transplant; chronic GVHD, no time limit.

GVHD, graft-versus-host disease; CMV, cytomegalovirus; VOD, veno-occlusive disease.

19 patients (67.9\%). The most common complications were cytomegalovirus (CMV) infection (13\%) and gastrointestinal mucositis (8\%), among mild nausea, abdominal pain, and diarrhea. Late complications other than GVHD developed in 10 patients (35.7\%). Endocrine dysfunction $(n=5)$ and pulmonary complications ( $n=5$ ) were the most common toxicities. Short stature and cataracts were reported in 4 and 
Table 6. Late complication from TBI

\begin{tabular}{rccccl}
\hline Age (yr) & Gender & Type & $\begin{array}{c}\text { Remission } \\
\text { status }\end{array}$ & $\begin{array}{c}\text { TBI } \\
\text { regimen } \\
\text { (Gy) }\end{array}$ & $\begin{array}{c}\text { Complication } \\
\text { (s) }\end{array}$ \\
\hline 12 & M & ALL & CR3 & 8 & Short stature \\
4 & F & AML & CR2 & 13.2 & $\begin{array}{l}\text { Cataract } \\
\text { Short stature }\end{array}$ \\
11 & F & AML & CR1 & 13.2 & VOD \\
6 & F & ALL & CR2 & 13.2 & Short stature \\
6 & M & AML & CR1 & 13.2 & VOD \\
& & & & & Cataract \\
& & & & & Short stature \\
\hline
\end{tabular}

TBI, total body irradiation; $A L L$, acute lymphoblastic leukemia; $A M L$, acute myeloid leukemia; $C R$, complete remission; VOD, veno-occlusive disease; short stature, defined as shorter than the third percentile of standard height and had not diagnosed before treatment.

2 patients, respectively. Endocrine dysfunction occurred in 5 patients, 3 patients were diagnosed with hypogonadism and 2 patients with hypothyroidism. Among the 3 patients with hypogonadism, 2 received hormone replacement.

\section{Discussion and Conclusion}

Allo-SCT is increasingly being used to treat children with acute leukemia, particularly in patients with high-risk disease. TBI was first reported in the 1970s, and has since been used as a conditioning regimen [14]. However at the time, the high dose of TBI resulted in a few patient fatalities. Consequently, radiation doses were reduced in order to improve safety during TBI. However, concerns regarding this type of treatment still remain about morbidity, and the complications associated with this treatment regimen, which may include cataracts, hypothyroidism, poor growth, neurocognitive effects, and risk of secondary neoplasms [15].

To reduce the incidence of adverse effects, numerous studies have attempted to replace TBI with chemotherapy in myeloablative conditioning, and RIC and non myeloablative conditioning were developed as a result. In this study, most patients (96.4\%) underwent myeloablative conditioning with TBI. Myeloablative preparation traditionally uses two regimens: cyclophosphamide (Cy) combined with $\mathrm{TB}$, or with busulfan (Bu). These regimens have been compared in several retrospective and randomized trials, and in a metaanalysis. No significant differences have been determined in terms of EFS, OS, acute or chronic GVHD, or interstitial pneumonitis [16-18]. However, non-TBI regimens conferred no advantage in reducing complications in comparison with TBI regimens. Furthermore, TBI has some advantages because it is not affected by blood flow or tumor site, and cheaper than chemotherapy. Hence, TBI with Cy remains the mainstay preparative regimen for myeloablative conditioning prior to allo-SCT. The development of advanced treatment strategies has enhanced clinical outcomes. However, TBI associated complications can cause irreversible damage and may lead to death when combined with allo-SCT related complications. Consequently, physicians need to monitor complications carefully, and patients must provide informed consent to receive all-SCT and TBI. However, few studies have investigated the results or complications associated with SCT and TBI treatment of Korean pediatric leukemia patients.

This single-institution retrospective study evaluated the effects of TBI-based conditioning prior to allo-SCT in pediatric acute leukemia patients; OS, EFS, TRM, and toxicity were investigated. The TBI treatment techniques vary depending on the machine, facility and characteristics of patients. Bilateral fields and parallel-opposed anterior/posterior (AP/PA) fields are commonly used in the conventional TBI treatment. The advantages of the AP/PA techniques include less variation in the thickness of the body in the superior-inferior direction and reduced radiation dose to the lungs. However, AP/PA techniques require the patients to be standing or lying on their side in our facility. Which is difficult to implement in pediatric patients, when considering the treatment duration, especially in, very young patients. Hence, the practice at our institution is typically to use the supine position

According to medical literature, 3- and 5-year EFS rates are reported to be 43\%-70\% [19-23] (Table 7). Although we investigated the 2-year EFS, our results are compatible with the findings of previous studies. We evaluated the 2-year EFS and OS rates leukemia type, remission status and source for transplantation. Although not statistically significant due to the small sample size of the current investigation, the EFS and OS in patients with AML were higher than in patients with $A L L$, in addition to the higher incidence of TRM in ALL. We found that that patients receiving peripheral blood stem cell transplantation during CR1 had the EFS and OS outcomes (not statistically significant). The largest proportion of fatalities was due to TRM. While improvements in chemotherapeutics have enable the use of higher doses in order to reduce in the relapse rates of leukemia patients, TRM still causes significant number of deaths. Previous studies have reported different rates of 
Table 7. Literature review of all-SCT

\begin{tabular}{|c|c|c|c|c|c|c|c|c|c|c|}
\hline Study & Disease & SCT type & Stage & No. & $\begin{array}{l}\text { Median } \\
\text { age (yr) }\end{array}$ & $2-y r$ OS (\%) & 2-yr EFS (\%) & $\begin{array}{c}\text { aGVHD } \\
(\geq \mathrm{Gr} \|, \%)\end{array}$ & $\begin{array}{c}\text { cGVHD }(\mathrm{Lm}+ \\
\left.\mathrm{Ex}_{1} \%\right)\end{array}$ & TRM (\%) \\
\hline Kang et al. [19] & AML & Auto & CR1 & 29 & 33 & $\mathrm{~N} / \mathrm{A}$ & $69(4-y r)$ & N/A & $N / A$ & 3.4 \\
\hline Blaise et al. [22] & AML & Allo-MSD & CR1 & 50 & 32 & 75.0 & 72 & 34.0 & 37.8 & 8.0 \\
\hline Ringden et al. [20] & $\begin{array}{l}\text { ALL } \\
\text { AML } \\
\text { CML }\end{array}$ & Allo-MSD & Any & $\begin{array}{l}20 \\
32 \\
26\end{array}$ & 34 & $76.0(3-y r)$ & $\begin{array}{l}50(3-y r) \\
64(3-y r) \\
83(3-y r)\end{array}$ & 22.0 & 35.0 & 9.0 \\
\hline Granados et al. [21] & ALL & Allo & Any & 114 & 18 & $N / A$ & $43(6-y r)$ & 30.3 & 7.9 (Ex only) & 22.0 \\
\hline Chou et al. [23] & $\begin{array}{l}\text { ALL } \\
\text { AML } \\
C M L\end{array}$ & Allo & Any & 58 & 8.4 & $\mathrm{~N} / \mathrm{A}$ & $\mathrm{N} / \mathrm{A}$ & 27.0 & 21.0 & 38.0 \\
\hline Present study & $\begin{array}{l}\text { ALL } \\
\text { AML }\end{array}$ & Allo & Any & $\begin{array}{r}21 \\
7\end{array}$ & 8 & $\begin{array}{l}52.5 \\
60.0\end{array}$ & $\begin{array}{l}64.3 \\
71.4\end{array}$ & 39.3 & 53.6 & 25.0 \\
\hline
\end{tabular}

Allo-SCT, allogeneic stem cell transplantation; OS, overall survival; EFS, event-free survival; aGVHD, acute graft versus host disease; CGVHD, chronic graft versus host disease; Gr, grade; Lm, limited; Ex, extensive; TRM, treatment related mortality; CR, complete remission; $A L L$, acute lymphoblastic leukemia; $A M L$, acute myeloid leukemia; $C M L$, Chronic myeloid leukemia; N/A, not acceptable.

TRM (3.5\%-38.0\%) arising from differences in the leukemia type (Table 7). Kang et al. [19] and Blaise et al. [22] reported TRM in AML patients exclusively. Ringden et al. [20] analyzed both AML and CML (Table 7). Our data show very low TRM in patients with AML (Table 4). However we found that TRM was higher in cases of $A L L$, in agreement with a recent report [24], where TRM was found to have decreased significantly from 33\% to 5\% over 25 years. The authors explained that the proportion of UCB contributed to reduction in TRM; however, in our study UCB transplantation failed to show improvement in EFS, OS or TRM outcomes. Of the 3 patients who received UCB transplantation, 1 died due to TRM, 1 died as a result of relapsed, and 1 showed chronic GVHD. Causes of TRM include pneumonia, graft failure, fungal infection, hemolytic uremic syndrome, acute respiratory distress syndrome, and hepatorenal syndrome. Non-myeloablative conditioning or RIC prior to SCT has been reported to decrease TRM [25], and RIC has lower toxic effects; however, RIC is currently administered to a select few patients at our institution. In our study, only 1 patient underwent non myeloablative conditioning and this patient died from relapsed ALL.

Nausea and vomiting were common during conditioning therapy, but were difficult to distinguish from chemotherapy associated complications. However, several complications are considered to be caused by TBI, including cataracts, hepatic VOD, short stature and secondary malignancy. Some studies have reported that TBI influences the final height $[26,27]$. Four patients developed growth retardation which is defined to be below the third percentile of standard height; these patients had no prior diagnosis of short stature. Two patients developed cataracts 25 and 32 months after TBI. While none of the patients developed secondary malignancies, our study had short follow-up considering the time required for to develop a secondary malignancy.

Five patients (17.9\%) were diagnosed with interstitial pneumonitis. Historically, interstitial pneumonitis has been found occur in nearly $40 \%$ of patients receiving TBI with a single, large fraction of 8-10 Gy [28]. Because interstitial pneumonia is related to the absolute absorbed dose of radiation in the lung, contemporary fractionated and lowdose TBI with concurrent chemotherapy decreases rate of interstitial pneumonitis. Our study findings are consistent with previous results in this instance $[29,30]$. Our institution uses a dose rate of less than $12 \mathrm{cGy} / \mathrm{min}$; this lower dose rate has been associated with reduced rates of pneumonitis, nausea, and vomiting [30]. Additional reductions in dose rate may decrease complications further, but may require more than 1 hour per fraction to deliver each fraction 2 sessions per day, an impractical option for both patients and clinicians.

The most serious complication of allogeneic transplantation is GVHD, an intricate immune response that develops following allogeneic stimulation. In our study, 11 patients (39.8\%) developed acute GVHD of a grade higher than II according to the criteria of Thomas et al. [10]. The clinical manifestations of chronic GVHD include not only skin dyspigmentation and nail dystrophy, but also symptoms resembling scleroderma and Sjögren syndrome, and can cause bronchiolitis, keratoconjunctivitis sicca, esophageal stricture, 
malabsorption, cholestasis, hematocytopenia, and generalized immunosuppression [31,32]. Using Shulman et al.'s criteria [13], 12 patients (42.9\%) developed extensive chronic GVHD. We found a higher incidence for acute and chronic GVHD in comparison with other TBI conditioning regimens.

The discrepancies in incidence of GVHD between this study and others may be explained by the fact that we analyzed pediatric patients, the differences in leukemia characteristics between studies, and the method by which GVHD was estimated. Our data indicate that, OS and EFS were not inferior to previous studies. Hence, given that GVHD is one of the major causes of death in leukemia patients, the most likely reason for the increased incidence of GVHD would be the difference in the leukemia characteristics in this study.

Other acute complications included CMV infection (46.4\%), mucositis (28.6\%), and nephropathy (21.4\%). Endocrine dysfunction and short stature were the primary late complications. Five patients (17.9\%) developed endocrine dysfunction and required endocrine therapy.

A lower total dose, a low-dose rate and fractionation during TBI reduces normal tissue toxicity [28], however, higher doses can improved survival outcomes for patients with leukemia $[33,34]$. Hence, the therapeutic ratio appears to be narrow. Comparisons of different TBI regimens are difficult because there have been few studies to date moreover there are many types of leukemia, each with a wide variety of characteristics. TBI regimen with a low dose rate and low dose per fraction may enable an increase in total dose. Techniques that improve conformity, such as field-in-field technique and tomotherapy, may enable an increase in the total dose of TBI as well. Further studies are needed in order to optimize the TBI regimen.

In summary, we evaluated acute pediatric leukemia patients who received allo-SCT with TBI conditioning, and the $\mathrm{TBI}$ conditioning was comparable with previous studies. However, allo-SCT with TBI conditioning can lead to severe complications. GVHD was the major complication in this study. Finally, all patients should receive support during the SCT and diligent follow minimize the impact of complications.

\section{Conflict of Interest}

No potential conflict of interest relevant to this article was reported.

\section{References}

1. Pulte D, Gondos A, Brenner H. Trends in 5- and 10-year survival after diagnosis with childhood hematologic malignancies in the United States, 1990-2004. J Natl Cancer Inst 2008;100:1301-9.

2. Creutzig U, Zimmermann M, Ritter J, et al. Treatment strategies and long-term results in paediatric patients treated in four consecutive AML-BFM trials. Leukemia 2005;19:203042.

3. Lange BJ, Smith FO, Feusner J, et al. Outcomes in CCG-2961, a children's oncology group phase 3 trial for untreated pediatric acute myeloid leukemia: a report from the children's oncology group. Blood 2008;111:1044-53.

4. Rovelli A, Arrigo C, Nesi F, et al. The role of thalidomide in the treatment of refractory chronic graft-versus-host disease following bone marrow transplantation in children. Bone Marrow Transplant 1998;21:577-81.

5. Wachowiak J, Malicki J, Buczkowski D, et al. Allogeneic bone marrow transplantation in children with acute lymphoblastic leukaemia in the first and second complete remission conditioned with fractionated total body irradiation and cyclophosphamide or etoposide. Rep Pract Oncol Radiother, 2002;7:117-25.

6. Sorror ML, Maris MB, Storb R, et al. Hematopoietic cell transplantation (HCT)-specific comorbidity index: a new tool for risk assessment before allogeneic HCT. Blood 2005;106:2912-9.

7. Sorror ML, Storer BE, Maloney DG, Sandmaier BM, Martin PJ, Storb R. Outcomes after allogeneic hematopoietic cell transplantation with nonmyeloablative or myeloablative conditioning regimens for treatment of lymphoma and chronic lymphocytic leukemia. Blood 2008;111:446-52.

8. Scott BL, Sandmaier BM, Storer B, et al. Myeloablative vs nonmyeloablative allogeneic transplantation for patients with myelodysplastic syndrome or acute myelogenous leukemia with multilineage dysplasia: a retrospective analysis. Leukemia 2006;20:128-35.

9. Ferrara JL, Levine JE, Reddy P, Holler E. Graft-versus-host disease. Lancet 2009;373:1550-61.

10. Przepiorka D, Weisdorf D, Martin P, et al. 1994 Consensus Conference on Acute GVHD Grading. Bone Marrow Transplant 1995; 15:825-8.

11. Thomas E, Storb R, Clift RA, et al. Bone-marrow transplantation (first of two parts). N Engl J Med 1975;292:832-43.

12. Thomas ED, Storb R, Clift RA, et al. Bone-marrow transplantation (second of two parts). N Engl J Med 1975;292:895-902.

13. Shulman HM, Sullivan KM, Weiden PL, et al. Chronic graftversus-host syndrome in man: a long-term clinicopathologic study of 20 Seattle patients. Am J Med 1980;69:204-17.

14. Fefer $A$, Einstein $A B$, Thomas $E D$, et al. Bone-marrow transplantation for hematologic neoplasia in 16 patients with identical twins. N Engl J Med 1974;290:1389-93. 
15. Shi-Xia X, Xian-Hua T, Hai-Qin X, Bo F, Xiang-Feng T. Total body irradiation plus cyclophosphamide versus busulphan with cyclophosphamide as conditioning regimen for patients with leukemia undergoing allogeneic stem cell transplantation: a meta-analysis. Leuk Lymphoma 2010;51:50-60.

16. Hartman AR, Williams SF, Dillon JJ. Survival, diseasefree survival and adverse effects of conditioning for allogeneic bone marrow transplantation with busulfan/ cyclophosphamide vs total body irradiation: a meta-analysis. Bone Marrow Transplant 1998;22:439-43.

17. Litzow MR, Perez WS, Klein JP, et al. Comparison of outcome following allogeneic bone marrow transplantation with cyclophosphamide-total body irradiation versus busulphancyclophosphamide conditioning regimens for acute myelogenous leukaemia in first remission. $\mathrm{Br} J$ Haematol 2002;119:1115-24.

18. Clift RA, Buckner CD, Thomas ED, et al. Marrow transplantation for chronic myeloid leukemia: a randomized study comparing cyclophosphamide and total body irradiation with busulfan and cyclophosphamide. Blood 1994;84:2036-43.

19. Kang KM, Choi BO, Chai GY, et al. Effect of cytarabine, melphalan, and total body irradiation as conditioning for autologous stem cell transplantation for patients with $\mathrm{AML}$ in first remission. J Korean Soc Ther Radiol Oncol 2003;21:192-8.

20. Ringden 0 , Ruutu $T$, Remberger $M$, et al. A randomized trial comparing busulfan with total body irradiation as conditioning in allogeneic marrow transplant recipients with leukemia: a report from the Nordic Bone Marrow Transplantation Group. Blood 1994;83:2723-30.

21. Granados E, de La Camara R, Madero L, et al. Hematopoietic cell transplantation in acute lymphoblastic leukemia: better long term event-free survival with conditioning regimens containing total body irradiation. Haematologica 2000;85: 1060-7.

22. Blaise $D$, Maraninchi $D$, Archimbaud $E$, et al. Allogeneic bone marrow transplantation for acute myeloid leukemia in first remission: a randomized trial of a busulfan-Cytoxan versus Cytoxan-total body irradiation as preparative regimen: a report from the Group d'Etudes de la Greffe de Moelle Osseuse. Blood 1992;79:2578-82.

23. Chou RH, Wong GB, Kramer JH, et al. Toxicities of total-body irradiation for pediatric bone marrow transplantation. Int J Radiat Oncol Biol Phys 1996;34:843-51.
24. Mateos MK, O'Brien TA, Oswald C, et al. Transplant-related mortality following allogeneic hematopoeitic stem cell transplantation for pediatric acute lymphoblastic leukemia: 25 -year retrospective review. Pediatr Blood Cancer 2013;60:1520-7.

25. Levine JE, Uberti JP, Ayash L, et al. Lowered-intensity preparative regimen for allogeneic stem cell transplantation delays acute graft-versus-host disease but does not improve outcome for advanced hematologic malignancy. Biol Blood Marrow Transplant 2003;9:189-97.

26. Cohen A, Rovelli $A$, Bakker $B$, et al. Final height of patients who underwent bone marrow transplantation for hematological disorders during childhood: a study by the Working Party for Late Effects-EBMT. Blood 1999;93:4109-15.

27. Nathan PC, Wasilewski-Masker K, Janzen LA. Long-term outcomes in survivors of childhood acute lymphoblastic leukemia. Hematol Oncol Clin North Am 2009;23:1065-82, vivii.

28. Keane TJ, Van Dyk J, Rider WD. Idiopathic interstitial pneumonia following bone marrow transplantation: the relationship with total body irradiation. Int J Radiat Oncol Biol Phys 1981;7:1365-70.

29. Shank B, Chu FC, Dinsmore $R$, et al. Hyperfractionated total body irradiation for bone marrow transplantation: results in seventy leukemia patients with allogeneic transplants. Int J Radiat Oncol Biol Phys 1983;9:1607-11.

30. Thomas ED, Clift RA, Hersman J, et al. Marrow transplantation for acute nonlymphoblastic leukemia in first remission using fractionated or single-dose irradiation. Int J Radiat Oncol Biol Phys 1982;8:817-21.

31. Copelan EA. Hematopoietic stem-cell transplantation. N Engl J Med 2006;354:1813-26.

32. Bhushan V, Collins RH Jr. Chronic graft-vs-host disease. JAMA 2003;290:2599-603.

33. Hows J, Bradley BA, Gore S, Downie T, Howard M, Gluckman E. Prospective evaluation of unrelated donor bone marrow transplantation. The International Marrow Unrelated Search and Transplant (IMUST) Study. Bone Marrow Transplant 1993;12:371-80.

34. Sierra J, Storer B, Hansen JA, et al. Unrelated donor marrow transplantation for acute myeloid leukemia: an update of the Seattle experience. Bone Marrow Transplant 2000;26:397-404. 